\title{
A GREY MULTI-OBJECTIVE LINEAR MODEL TO FIND CRITICAL PATH OF A PROJECT BY USING TIME, COST, QUALITY AND RISK PARAMETERS
}

\author{
Hannan Amoozad Mahdiraji, Seyed Hossein Razavi Hajiagha, \\ Shide Sadat Hashemi, Edmundas Kazimieras Zavadskas
}

\section{Introduction}

In today's highly competitive business environment, project management's ability to schedule activities and monitor progress within strict cost, time and performance guidelines is becoming increasingly significant to attain competitive priorities such as on time delivery and customization (Chen, 2007). Project management is one of the most important fields in business and industry. Any task in an organization can be taken into account as a project, i.e., a temporary endeavor undertaken to produce a unique product or service. In this context, the purpose of project management is to foresee as many of the dangers and problems as possible in addition to plan, organize, and control activities so that the projects will be completed successfully despite all the exposed risks (Razavi Hajiagha et al., 2014).

The project network is defined as a set of activities which are performed according to the precedence constraint of the activities. A network path is a path from the beginning node to the last node. The path length is equal to total duration of the activities duration performed through the path. The accomplishment duration of the project is equal to length of the lengthiest network path which is called the critical path. The project is accomplished when all the activities existing in the critical path have been accomplished (Shahsavaripour et al, 2010). One basic problem when scheduling an activity network representing a project is finding the critical activities, and determining optimal starting times of the activities, so as to minimize the make span. The first step is to determine the earliest ending time of the project (Malcolm et al., 1959).
To maximize resource utilization and to minimize overall cost, project management has always been an important issue for public agencies and industrial organizations. The network techniques used to tackle project analysis are Critical Path Method (hereafter CPM) and Project Evaluation and Review Technique (PERT) (Taylor, 1996; Shankar et al., 2010; Elizabeth \& Sujatha, 2013).

CPM, worked out at the beginning of the 1960s, has become one of the most useful tools in practice and is applied in planning and control the realization of complex projects (Kelly, 1961). The purpose is to identify critical activities on the critical path so that the resources may be concentrated on these activities in order to reduce project length time (Kumar \& Kaur, 2010; Kaur \& Kumar, 2014). Besides, CPM has been proved very valuable in evaluating the project performance and also for identifying the bottlenecks. Thus, CPM is a vital tool for planning and control of the complex projects.

CPM is widely used in project scheduling and controlling. In conventional project scheduling problem, the crisp numbers are used for the activity times. However in reality, it is an unrealistic assumption in an imprecise and uncertain environment (Chen \& Hseuh, 2008; Shankar \& Saradhi, 2011). In a large scale project, the working procedure time is usually uncertain for some existing uncertain factors (Prade, 1979). Further implementation of CPM requires availability of the clearly determined time duration for each activity. To deal with the real life situations, different uncertainty frameworks are proposed, including fuzzy set theory, interval numbers and probability and statistics. 
Zadeh introduce the concept of fuzzy set (Zadeh, 1965). There is always some uncertainty about time duration of the activities in the network planning, due to which the fuzzy critical path method (FCPM) was proposed since the late 1970s (Kumar \& Kaur, 2010).

Many researches focused on development of a new fuzzy critical path method based on the fuzzy set theory to solve the project scheduling problem under the fuzzy environment (Kumar \& Kaur, 2010; Kaur \& Kumar, 2014; Chen \& Hsueh, 2008; Shankar \& Saradhi, 2011; Liang \& Han, 2004). As an application, Han, Chung, and Liang (Han et al., 2006) demonstrated a model for how to employ the Fuzzy Critical Path method (CPM) to find out airport's ground critical operation processes.

Elizabeth and Sujatha (2013) proposed a new ranking method to identify the fuzzy critical path and the fuzzy critical length. Similarly, Sireesha and Shankar (2010) introduced a new method based on the fuzzy theory to solve the project scheduling problem under the fuzzy environment. In addition, Shankar et al. (2010) presented a method for finding the critical path in the fuzzy project network, by applying two ranking procedures on the fuzzy numbers: one using individual ranking of fuzzy numbers and the other applying the set of fuzzy numbers to the proposed critical path method. They also suggested a metric distance ranking method for the fuzzy numbers to a critical path method for the fuzzy project network, where the time duration of each activity in a fuzzy project network is represented by a trapezoidal fuzzy number (Shankar et al., 2010).

Fuzzy linear programming application in estimation of the project duration was also investigated by many researchers. Shahsavaripour et al. (2010) developed a model for estimating duration of the project accomplishment and determining the project critical path through resolving a fuzzy linear programming model. Besides, Madhuri et al. (2013) proposed a new fuzzy linear programming model to find the fuzzy critical path and the fuzzy completion time of a fuzzy project.

Moreover, Grey and interval numbers are considered as new approaches to add uncertainty in the reality situations. Huang et al. (1996) presented a new CPM method based on the grey numbers for planning construction projects. Chanas and Zielinski (2002) later proposed a model to identify the CPM consisting of interval valued parameters. Previously they also presented two methods of calculation of the path degree of criticality (Chanas \& Zielinski, 2001). Sireesha et al. (2012) proposed a model for determining the fuzzy interval time of completing the fuzzy project and also finding the critical path of the fuzzy project network. Moreover, grey mathematical programming models were employed for Time-Cost-Quality trade-offs in project management considering uncertain situations. (Amoozad Mahdiraji et al., 2011; Razavi et al., 2014; Razavi et al., 2015)

Considering the fuzzy and interval approaches for estimation of project floats (such as total, free or independent float) is also applicable. Fortin et al. (2010) introduced a model to assert possible and necessary criticality of the different tasks and to compute their earliest possible starting dates, latest possible starting dates and floats. Shankar et al. (2010) employed a new defuzzification formula for a trapezoidal fuzzy number and applied it to the float time (slack time) for each activity in the fuzzy project network to get the critical path.

The above mentioned works considered the time as a unique factor of project successful management. However, a more refined viewpoint toward project management required that a successful project must satisfy its customers' needs within a reasonable budget and a logical time (Rasmy et al., 2008). These three criteria namely quality, cost, and time along with risk constituted a multi criteria nature for measurement and evaluation of the project success. In this course, a new definition of the critical path can be expressed as a path in the project graph with the maximum time, cost, quality, and risk. Therefore, the problem of critical path finding would be rendered as a multi criteria problem. Adding the property of uncertainty, this problem will become an uncertain multi criteria decision making problem. (Zammori et al., 2009) integrated fuzzy logic and multi criteria decision making method to find the critical path of a project, considering several factors. Amiri and Golozari (2011) introduced an algorithm based on fuzzy TOPSIS which considers not only the time factor but also the cost, risk, and quality criteria to determine the critical path under the fuzzy environment. Cristobal (2013) considered time, cost, quality and safety factors to address the 
multi criteria critical path of a project, applying fuzzy PROMETHEE method.

The aim of this paper is to develop a multiple objective programming formulation and to propose a solving approach to find the critical path of a project, considering not only the time, but also the cost, quality and risk criteria. Alongside, the inherent uncertainty of approximating these parameters is handled by defining them as grey numbers. For this matter, a grey multi-objective linear programming model is proposed containing four objectives. Moreover, a solution approach is extended based on goal programming to find the multi criteria critical path (MCCP) of a project.

The remainder of paper is organized as follows. A brief overview on grey numbers is given in Section 1. The model formulation is explained in Section 2 and the proposed solving approach is introduced in Section 3. Then, a numerical example is solved in Section 4. Finally, the paper is concluded in the last Section.

\section{An Overview on Grey Numbers}

Decision making problems always need some information to deal with a given problem. Usually, this information is not available as deterministic data. Human information is often partial or approximates (Traub \& Werschulz, 1998). Therefore, it is necessary to have some frameworks for analyzing the uncertain problems with ill-defined data. Liu and Lin (2006) categorized different approaches for uncertain problems into (1) statistic and probability, (2) fuzzy set theory, and (3) Grey systems. In this paper, it is assumed that incomplete information is determined with grey numbers. A great advantage of this approach in comparison with the conventional statistic or fuzzy frameworks is that it does not need any assumption about probability distribution or membership function form of information (Li et al., 2014).

Grey systems developed by Deng (1982) and Deng (1989) present grey decision-making systems. Many other researchers applied this concept in their decision-making problems. There are several types of grey numbers which are reviewed by Liu and Lin (2010). Interval grey numbers are a common form of the grey numbers. The exact values of these numbers are unknown, but they usually lie within a known range (Liu \& Lin, 2010; Lin et al., 2004).
Interval grey number is a number with both lower and upper bounds, $\tilde{x} \in[\underline{x}, \bar{x}]$, where $\underline{x} \leq \bar{x}$. The main arithmetic operations can be defined on interval numbers. Let $\tilde{x}_{1}=\left[\underline{x}_{1}, \bar{x}_{1}\right]$ and $\tilde{x}_{2}=\left[x_{2}, \bar{x}_{2}\right]$ be two interval numbers. The following operations can be defined as (Liu \& Lin, 2006):

$$
\begin{aligned}
& \tilde{x}_{1}+\tilde{x}_{2}=\left[\underline{x}_{1}+\underline{x}_{2}, \bar{x}_{1}+\bar{x}_{2}\right] \\
& \tilde{x}_{1}-\tilde{x}_{2}=\left[\underline{x}_{1}-\bar{x}_{2}, \bar{x}_{1}-\underline{x}_{2}\right] \\
& \tilde{x}_{1} \times \tilde{x}_{2}=\left[\begin{array}{l}
\min \left(\underline{x}_{1} \underline{x}_{2}, \underline{x}_{1} \bar{x}_{2}, \bar{x}_{1} \underline{x}_{2}, \bar{x}_{1} \bar{x}_{2}\right), \\
\max \left(\underline{x}_{1} \underline{x}_{2}, \underline{x}_{1} \bar{x}_{2}, \bar{x}_{1} \underline{x}_{2}, \bar{x}_{1} \bar{x}_{2}\right)
\end{array}\right] \\
& \tilde{x}_{1} \div \tilde{x}_{2}=\left[\underline{x}_{1}, \bar{x}_{1}\right] \times\left[\frac{1}{\bar{x}_{2}}, \frac{1}{\underline{x}_{2}}\right]
\end{aligned}
$$

\section{Multi-objective Grey Critical Path Modeling}

As mentioned before, the main goal of this paper is to suggest a model for determining the critical path of a project, while considering cost, quality and risk criteria, in addition to the classic time criterion. A project can be defined as a directed acyclic graph $G=(V, E)$, where $V$ is the set of $m$ nodes and $E=\{(i, j), \ldots,(l, m)\}$ is the set of $n$ directed graphs between nodes. These nodes and arcs represent the project's activities and events, respectively.

One of the efficient approaches for finding critical paths and total duration time of the project networks is the linear programming formulation. A CPM problem can be thought as opposite to the shortest path problem (Taha, 2003). To determine a critical path in the project network it suffices finding the longest path from the starting to the final node. The length of this longest path presents the total duration of the project network. In this formulation, time is the only objective of the problem. Let $t_{i j}$ be the completion time of activity $(i, j) \in E$, and the CPM problem with $n$ nodes is formulated as: 
$\max T=\sum_{i=1}^{n} \sum_{j=1}^{n} t_{i j} x_{i j}$

S.T.

$\sum_{j=1}^{n} x_{1 j}=1$,

$\sum_{j=1}^{n} x_{i j}=\sum_{k=1}^{n} x_{k i}, i=2, \ldots, n-1$,

$\sum_{k=1}^{n} x_{k n}=1$,

$x_{k n} \geq 0,(i, j) \in E$

where $x_{i j}$ denotes the decision variable denoting the amount of flow in activity $(i, j) \in E$. The constraints of problem (5) represent the conservation of flow at each node, i.e. no flow may be created or destroyed in the project network. As a form of shortest path problem, all the basic feasible variables in each basic feasible solution to model (5) are binary (Taha, 2003). Those activities which their corresponding variables take a value of 1 in the optimal solution, determine the critical path of the network with maximum completion time.

This form of critical path determination, neglect the other important criteria like cost, quality and risk. Furthermore, the parameters of this problem, including activity time, are determined as the crisp numbers. Here in this section a new formulation of critical path is introduced. Accordingly, critical path of a network is a sequence of activities with the highest time, cost, quality and risk. In fact, critical path needs maximum time while it has the maximum risk, cost and quality. Therefore, the critical path determination problem is formulated as a multi-objective problem. Let $\widetilde{t}_{i j} \in\left[\underline{t}_{i j}, \bar{t}_{i j}\right], \quad \widetilde{c}_{i j} \in\left[\underline{c}_{i j}, \bar{c}_{i j}\right], \quad \widetilde{q}_{i j} \in\left[q_{i j}, \bar{q}_{i j}\right]$ and $\widetilde{r}_{i j} \in\left[\underline{r}_{i j}, \bar{r}_{i j}\right]$ be the time, cost, quality and risk approximations of the activity $(i, j) \in E$, respectively. Considering the uncertainty and ill-defined data, these parameters are approximated in the form of grey numbers. Critical path of the network $G=(V, E)$ can be determined solving the below problem.

$$
\begin{aligned}
& \max \widetilde{T}=\sum_{i=1}^{n} \sum_{j=1}^{n} \widetilde{t}_{i j} x_{i j} \\
& \max \widetilde{C}=\sum_{i=1}^{n} \sum_{j=1}^{n} \widetilde{c}_{i j} x_{i j} \\
& \max \widetilde{Q}=\sum_{i=1}^{n} \sum_{j=1}^{n} \widetilde{q}_{i j} x_{i j} \\
& \max \widetilde{R}=\sum_{i=1}^{n} \sum_{j=1}^{n} \widetilde{r}_{i j} x_{i j}
\end{aligned}
$$

S.T.

$\sum_{j=1}^{n} x_{1 j}=1$,

$\sum_{j=1}^{n} x_{i j}=\sum_{k=1}^{n} x_{k i}, i=2, \ldots, n-1$,

$\sum_{k=1}^{n} x_{k n}=1$,

$x_{k n} \geq 0,(i, j) \in E$

where $\widetilde{T}, \widetilde{C}, \widetilde{Q}$ and $\widetilde{R}$ represent the total time, cost, quality and risk of the problem which are maximized to find the multi-objective critical path of the project.

\section{Solution Procedure}

The model (6) is a grey multi-objective linear programming (GMOLP) problem; and therefore, it is likely that there will be no global optimal solution. In fact, it is possible that no path can be found in the network that has the maximum time, cost, quality and risk simultaneously. However, the multi-objective approaches find the efficient (Pareto optimal) solutions of the problem as preferred solutions (Tanino et al., 2003; Branke et al., 2008). Some procedures are suggested for solving the grey multiobjective linear programming problems among which one can refer to Wang and Wang (2001), Ida (2005), and Razavi Hajiagha et al. (2013). However, the method presented in this paper is inspired from goal programming methodology (Charnes \& Cooer, 1961) due to its simplicity and well known logic.

To avoid a misleading effect of the parameters on the optimal solutions, initially all the time, cost, quality and risk parameters are normalized. Considering their grey form, the normalized time related parameters are 
determined as follows:

$$
\widetilde{t}_{i j}{ }^{n}=\left[\underline{t}_{i j}^{n}, \bar{t}_{i j}^{n}\right]=\left[\frac{\underline{t}_{i j}}{\bar{t}_{i j}^{*}}, \frac{\bar{t}_{i j}}{\bar{t}_{i j}^{*}}\right]
$$

where $\bar{t}_{i j}^{*}=\max _{(i, j) \in E} \bar{t}_{i j}$. For cost, quality, and risk parameters the following relations are applied:

$$
\begin{aligned}
& \tilde{c}_{i j}^{n}=\left[\underline{c}_{i j}^{n}, \bar{c}_{i j}^{n}\right]=\left[\frac{\underline{c}_{i j}}{\bar{c}_{i j}^{*}}, \frac{\bar{c}_{i j}}{\bar{c}_{i j}^{*}}\right] \\
& \tilde{q}_{i j}^{n}=\left[\underline{q}_{i j}^{n}, \bar{q}_{i j}^{n}\right]=\left[\frac{\underline{q}_{i j}}{\bar{q}_{i j}^{*}}, \frac{\bar{q}_{i j}}{\bar{q}_{i j}^{*}}\right] \\
& \tilde{r}_{i j}^{n}=\left[\underline{r}_{i j}^{n}, \bar{r}_{i j}^{n}\right]=\left[\frac{\underline{r}_{i j}}{\bar{r}_{i j}^{*}}, \frac{\bar{r}_{i j}}{\bar{r}_{i j}^{*}}\right]
\end{aligned}
$$

where $\quad \bar{c}_{i j}^{*}=\max _{(i, j) \in E} \bar{c}_{i j}, \quad \bar{q}_{i j}^{*}=\max _{(i, j) \in E} \bar{q}_{i j}, \quad$ and $\bar{r}_{i j}^{*}=\max _{(i, j) \in E} \bar{r}_{i j}$.

The next step to propose a goal programming based approach for solving model (6) is to determine a set of goals for each objective. Suppose that the set of feasible solutions for this model (i.e. the set of solution which satisfied the constraints of the model) is presented by FS. Consider the time objective. Applying the algebraic operation of intervals, Eqs. (1)-(4), on this objective, an interval objective function will be provided as follows:

$$
\max \widetilde{T}=\left[\sum_{i=1}^{n} \sum_{j=1}^{n} t_{i j}^{n} x_{i j}, \sum_{i=1}^{n} \sum_{j=1}^{n} \bar{t}_{i j}^{n} x_{i j}\right]
$$

Now, to form a goal for the time criterion, the following two problems are solved:

$$
\max \underline{T}=\sum_{i=1}^{n} \sum_{j=1}^{n} \underline{t}_{i j}^{n} x_{i j}
$$

S.T.

$\mathrm{x} \in F S$

and

$$
\max \bar{T}=\sum_{i=1}^{n} \sum_{j=1}^{n} \bar{t}_{i j}^{n} x_{i j}
$$

S.T.

$\mathrm{x} \in F S$

Solving models (8) and (9), the optimal lower bound, $\underline{T}^{*}$, and upper bound, $\bar{T}^{*}$, for total completion time of project are specified, respectively. This optimal goal can be represented as $\widetilde{T}^{*} \in\left[\underline{T}^{*}, \bar{T}^{*}\right]$.

Similarly, the goals of cost, quality, and risk criteria are determined by replacing their corresponding lower bound and upper bound functions in Eqs. (8) and (9), by using the normalized coefficients in Eqs. (8)-(10). Solving the corresponding models of cost, quality and risk, $\quad \widetilde{C}^{*} \in\left[\underline{C}^{*}, \bar{C}^{*}\right], \quad \widetilde{Q}^{*} \in\left[\underline{Q}^{*}, \bar{Q}^{*}\right]$, and $\widetilde{R}^{*} \in\left[\underline{R}^{*}, \bar{R}^{*}\right]$ goals will be determined.

To determine the Pareto optimal critical path of the problem, it remains to solve a goal programming problem in order to minimize the total sum of deviations from different goals. This problem can be formulated as follows:

$$
\min \sum_{k=1}^{8} d_{k}^{-}
$$

S.T.

$\sum_{i=1}^{n} \sum_{j=1}^{n} \underline{t}_{i j}^{n} x_{i j}+d_{1}^{-}-d_{1}^{+}=\underline{T}^{*}$
$\sum_{i=1}^{n} \sum_{j=1}^{n} \bar{t}_{i j}^{n} x_{i j}+d_{2}^{-}-d_{2}^{+}=\bar{T}^{*}$

$\sum_{i=1}^{n} \sum_{j=1}^{n} \underline{c}_{i j}{ }^{n} x_{i j}+d_{3}^{-}-d_{3}^{+}=\underline{C}^{*}$

$\sum_{i=1}^{n} \sum_{j=1}^{n} \bar{c}_{i j}{ }^{n} x_{i j}+d_{4}^{-}-d_{4}^{+}=\bar{C}^{*}$

$\sum_{i=1}^{n} \sum_{j=1}^{n} \underline{q}_{i j}^{n} x_{i j}+d_{5}^{-}-d_{5}^{+}=\underline{Q}^{*}$

$\sum_{i=1}^{n} \sum_{j=1}^{n} \bar{q}_{i j}{ }^{n} x_{i j}+d_{6}^{-}-d_{6}^{+}=\bar{Q}^{*}$

$\sum_{i=1}^{n} \sum_{j=1}^{n} \underline{r}_{i j}^{n} x_{i j}+d_{7}^{-}-d_{7}^{+}=\underline{R}^{*}$

$\sum_{i=1}^{n} \sum_{j=1}^{n} \bar{r}_{i j}^{n} x_{i j}+d_{8}^{-}-d_{8}^{+}=\bar{R}^{*}$

$\mathrm{x} \in F S$ 


\section{Ekonomika a management}

Solving the above goal programming problem, the multi-objective critical path of the problem is determined as an efficient solution of problem (6).

If project manager has a preemptive preferential structure over four objectives, i.e. he/she assigned some weights of $\lambda_{p} \geq 0, p=1,2,3,4$ to the time, cost, quality, and risk criteria that $\sum_{p=1}^{4} \lambda_{p}=1$, respectively (these weights can be determined using either pairwise comparisons or an intuitionistic approach), then the objective function of Eq. (14) will become as follows:

$$
\begin{array}{r}
\min \lambda_{1}\left(d_{1}^{-}+d_{1}^{+}+d_{2}^{-}+d_{2}^{+}\right)+\lambda_{2}\left(d_{3}^{-}+d_{3}^{+}+d_{4}^{-}+d_{4}^{+}\right) \\
+\lambda_{3}\left(d_{5}^{-}+d_{5}^{+}+d_{6}^{-}+d_{6}^{+}\right)+\lambda_{4}\left(d_{7}^{-}+d_{7}^{+}+d_{8}^{-}+d_{8}^{+}\right)
\end{array}
$$

An algorithmic scheme of the proposed interval multi-objective critical path model is presented as figure 1.

It is notable that this algorithm includes solving nine models to determine goal values and a goal programming problem to find the efficient critical path. However, since the eight models of goal values finding have similar constraints, the only remaining thing is to change their objective function. Also, the final goal programming problem has just eight additional constraints as compared to the initial goal finding models. Considering abilities of the available optimization packages, this algorithm doesn't seem too onerous.

\section{Numerical Example}

This section presents a numerical example of determining multi-objective critical path of a project with the interval data. Consider a project including 29 activities as illustrated in Fig. 2.

The information of project's activities is presented in table 1 , including the activities time, cost, quality, and risk parameters' approximation in an interval form.

Then, the information in table 1 is normalized applying Eqs. (7) - (10). The result is presented in table 2.

In the next step, the goal values are determined for time, cost, quality and risk criteria, solving the corresponding problems of (12) and (13) with the associated parameters. Now, one can consider the time criterion, and the above mentioned problems become as follows:

\section{Fig. 1: The proposed algorithm}

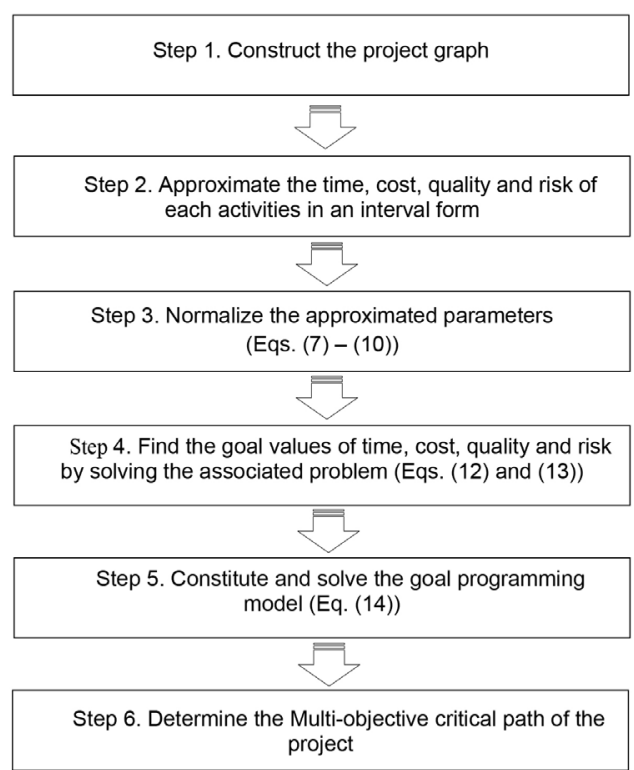




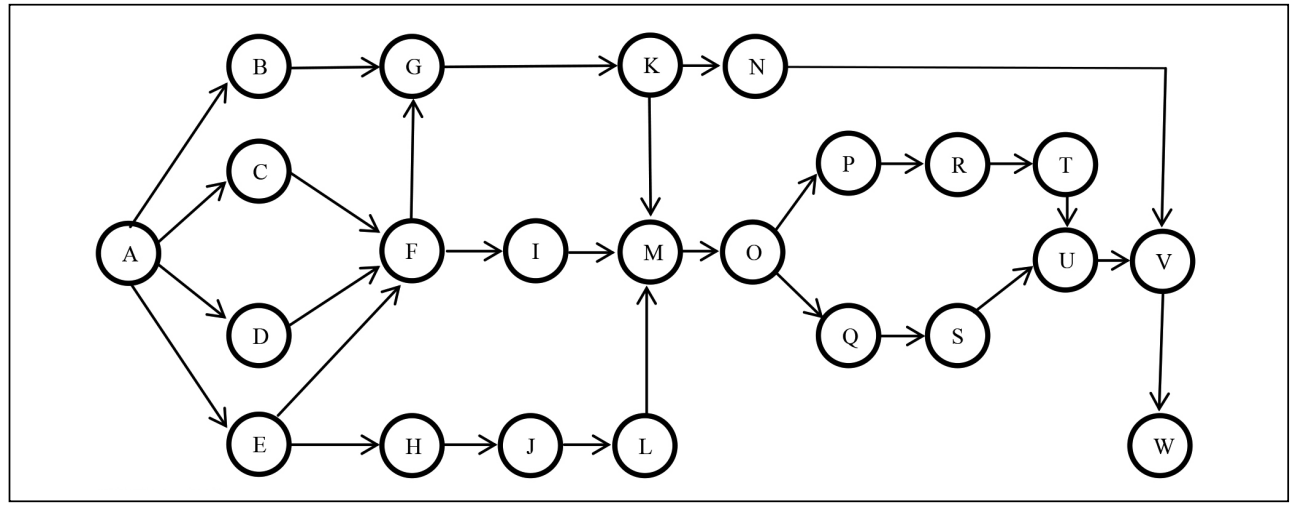

Source: own

$\max \underline{T}=0.208 x_{A B}+0.375 x_{A C}+0.542 x_{A D}+0.417 x_{A D}+\ldots$ $+0.667 x_{T U}+0.583 x_{N V}+0.542 x_{U V}+0.833 x_{V W}$ S.T.

$$
F S:\left\{\begin{array}{l}
x_{A B}+x_{A C}+x_{A D}++x_{A E}=1 \\
x_{A B}=x_{B G} \\
x_{A C}=x_{C F} \\
x_{A D}=x_{D F} \\
\vdots \\
x_{R T}=x_{T U} \\
x_{T U}+x_{S U}=x_{U V} \\
x_{U V}=x_{V W} \\
x_{V W}=1 \\
x_{i j} \geq 0, i, j \in\{A, B, \ldots, W\}
\end{array}\right.
$$

Solving the above problem, the lower bound time-based critical path is determined as $x_{A D} \rightarrow$ $x_{D F} \rightarrow x_{F I} \rightarrow x_{I M} \rightarrow x_{M O} \rightarrow x_{O P} \rightarrow x_{P R} \rightarrow x_{R T}$ $\rightarrow x_{T U} \rightarrow x_{U V} \rightarrow x_{V W}$ with an objective value of $T^{*}=5.709$. The following problem is solved for finding the upper bound of time based critical path:

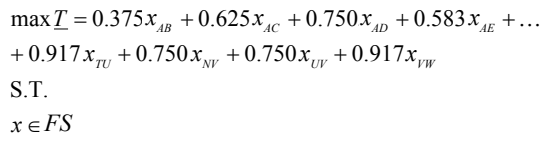

Solving the above mentioned problem, the upper bound time-based critical path is identified as $x_{A D} \rightarrow x_{D F} \rightarrow x_{F G} \rightarrow x_{G K} \rightarrow x_{K M}$ $\rightarrow x_{M O} \rightarrow x_{O P} \rightarrow x_{P R} \rightarrow x_{R T} \rightarrow x_{T U} \rightarrow x_{U V} \rightarrow$ $x_{V W}$ with an objective value of $\bar{T}^{*}=7.874$.
Therefore, the interval time goal of critical path problem is determined as $T^{*} \in[5.709,7.874]$. Similarly, replacing the associated cost, quality and risk parameters from table 2, the corresponding goals are determined and are listed in table 3.

At the final step, the goal programming problem, Eq. (14), is formulated and solved considering the goal values. The multi-objective critical path is determined as $x_{A C} \rightarrow x_{C F} \rightarrow x_{F G}$ $\rightarrow x_{G K} \rightarrow x_{K M} \rightarrow x_{M O} \rightarrow x_{O P} \rightarrow x_{P R} \rightarrow x_{R T} \rightarrow x_{T U}$ $\rightarrow x_{U V} \rightarrow x_{V W}$ with a total time of [18, 27], total cost of $[440,530]$, total quality of [8.45, 9.55], and total risk of $[2.6,3.85]$.

\section{Conclusion}

Many activities of an organization can be viewed in the form of projects. A project is a series of related activities which are organized to reach a defined goal or satisfy a certain need. Critical path method is a well-known and widely accepted method to find the critical activities of a project and to concentrate on them for accomplishment of the project without any deviation. Classic CPM method is devoted to find critical path of a project by considering only the time of activities. However, today it is an accepted phenomenon that cost, quality, and risk criteria must be considered along with time criterion to a successful project management. On the other hand, the project planning methods require some priori approximation of the project activities about time, cost, quality, and risk parameters, but the project managers always 


\section{Ekonomika a management}

\begin{tabular}{|c|c|c|c|c|c|}
\hline Row & Activity & Time & Cost & Quality & Risk \\
\hline 1 & $A-B$ & {$[5,9]$} & {$[1200,1500]$} & {$[55 \%, 65 \%]$} & {$[10 \%, 25 \%]$} \\
\hline 2 & $\mathrm{~A}-\mathrm{C}$ & {$[9,15]$} & {$[1800,2300]$} & {$[80 \%, 90 \%]$} & {$[20 \%, 30 \%]$} \\
\hline 3 & $A-D$ & {$[13,18]$} & {$[2970,3200]$} & {$[70 \%, 85 \%]$} & {$[10 \%, 20 \%]$} \\
\hline 4 & $A-E$ & {$[10,14]$} & {$[2000,2600]$} & {$[90 \%, 95 \%]$} & {$[30 \%, 35 \%]$} \\
\hline 5 & $B-G$ & {$[13,16]$} & {$[2100,2500]$} & {$[55 \%, 65 \%]$} & {$[25 \%, 35 \%]$} \\
\hline 6 & C-F & {$[7,13]$} & {$[2550,2900]$} & {$[90 \%, 95 \%]$} & {$[20 \%, 35 \%]$} \\
\hline 7 & D-F & {$[5,11]$} & {$[1100,1350]$} & {$[80 \%, 90 \%]$} & {$[20 \%, 30 \%]$} \\
\hline 8 & $E-F$ & {$[3,5]$} & {$[890,1400]$} & {$[75 \%, 85 \%]$} & {$[35 \%, 40 \%]$} \\
\hline 9 & $\mathrm{E}-\mathrm{H}$ & {$[3,9]$} & {$[950,1360]$} & {$[75 \%, 85 \%]$} & {$[40 \%, 50 \%]$} \\
\hline 10 & $F-G$ & {$[9,14]$} & {$[1700,1990]$} & {$[85 \%, 90 \%]$} & {$[20 \%, 30 \%]$} \\
\hline 11 & $\mathrm{~F}-\mathrm{I}$ & {$[17,22]$} & {$[2120,3000]$} & {$[70 \%, 80 \%]$} & {$[40 \%, 45 \%]$} \\
\hline 12 & G-K & {$[3,8]$} & {$[2800,3500]$} & {$[80 \%, 85 \%]$} & {$[30 \%, 40 \%]$} \\
\hline 13 & $\mathrm{H}-\mathrm{J}$ & {$[3,5]$} & {$[1200,1650]$} & {$[50 \%, 65 \%]$} & {$[10 \%, 20 \%]$} \\
\hline 14 & I-M & {$[4,8]$} & {$[950,1400]$} & {$[60 \%, 70 \%]$} & {$[25 \%, 35 \%]$} \\
\hline 15 & $J-L$ & {$[3,8]$} & {$[1200,1600]$} & {$[55 \%, 65 \%]$} & {$[35 \%, 45 \%]$} \\
\hline 16 & K-M & {$[8,11]$} & {$[2000,2850]$} & {$[45 \%, 55 \%]$} & {$[25 \%, 30 \%]$} \\
\hline 17 & $\mathrm{~K}-\mathrm{N}$ & {$[17,21]$} & {$[3010,3300]$} & {$[75 \%, 80 \%]$} & {$[20 \%, 25 \%]$} \\
\hline 18 & L-M & {$[14,16]$} & {$[2500,2900]$} & {$[60 \%, 75 \%]$} & {$[20 \%, 30 \%]$} \\
\hline 19 & $\mathrm{M}-\mathrm{O}$ & {$[16,20]$} & {$[2300,2650]$} & {$[70 \%, 80 \%]$} & {$[15 \%, 25 \%]$} \\
\hline 20 & O-P & {$[19,24]$} & {$[2700,3000]$} & {$[45 \%, 55 \%]$} & {$[25 \%, 35 \%]$} \\
\hline 21 & $\mathrm{O}-\mathrm{Q}$ & {$[14,17]$} & {$[2620,3100]$} & {$[75 \%, 85 \%]$} & {$[25 \%, 30 \%]$} \\
\hline 22 & $\mathrm{P}-\mathrm{R}$ & {$[9,12]$} & {$[2400,2860]$} & {$[60 \%, 70 \%]$} & {$[10 \%, 15 \%]$} \\
\hline 23 & Q-S & {$[15,18]$} & {$[3000,3150]$} & {$[75 \%, 80 \%]$} & {$[20 \%, 25 \%]$} \\
\hline 24 & R-T & {$[5,9]$} & {$[1680,2200]$} & {$[65 \%, 75 \%]$} & {$[25 \%, 35 \%]$} \\
\hline 25 & S-U & {$[15,17]$} & {$[2300,2700]$} & {$[50 \%, 60 \%]$} & {$[25 \%, 40 \%]$} \\
\hline 26 & $T-U$ & {$[16,22]$} & {$[3800,4100]$} & {$[80 \%, 90 \%]$} & {$[35 \%, 45 \%]$} \\
\hline 27 & $\mathrm{~N}-\mathrm{V}$ & {$[14,18]$} & {$[2900,3300]$} & {$[65 \%, 70 \%]$} & {$[30 \%, 40 \%]$} \\
\hline 28 & U-V & {$[13,18]$} & {$[3100,3500]$} & {$[75 \%, 85 \%]$} & {$[20 \%, 30 \%]$} \\
\hline 29 & V-W & {$[20,22]$} & {$[2800,3250]$} & {$[70 \%, 85 \%]$} & {$[25 \%, 35 \%]$} \\
\hline
\end{tabular}

\section{Tab. 2: Normalized parameters - Part 1}

\begin{tabular}{c|c|c|c|c|c} 
Row & Activity & Time & Cost & Quality & Risk \\
\hline 1 & A-B & {$[0.208,0.375]$} & {$[0.293,0.366]$} & {$[0.579,0.684]$} & {$[0.2,0.5]$} \\
\hline 2 & A-C & {$[0.375,0.625]$} & {$[0.439,0.561]$} & {$[0.842,0.947]$} & {$[0.4,0.6]$} \\
\hline 3 & A-D & {$[0.542,0.750]$} & {$[0.724,0.780]$} & {$[0.737,0.895]$} & {$[0.2,0.4]$} \\
\hline 4 & A-E & {$[0.417,0.583]$} & {$[0.488,0.634]$} & {$[0.947,1]$} & {$[0.6,0.7]$} \\
\hline 5 & B-G & {$[0.542,0.667]$} & {$[0.512,0.610]$} & {$[0.579,0.684]$} & {$[0.5,0.7]$} \\
\hline
\end{tabular}




\begin{tabular}{c|c|c|c|c|c}
\multicolumn{7}{c}{ Tab. 2: } & Normalized parameters - Part 2 \\
Row & Activity & Time & Cost & Quality & Risk \\
\hline 6 & C-F & {$[0.292,0.542]$} & {$[0.622,0.707]$} & {$[0.947,1]$} & {$[0.4,0.7]$} \\
\hline 7 & D-F & {$[0.208,0.458]$} & {$[0.268,0.329]$} & {$[0.842,0.947]$} & {$[0.4,0.6]$} \\
\hline 8 & E-F & {$[0.125,0.208]$} & {$[0.217,0.341]$} & {$[0.789,0.895]$} & {$[0.7,0.8]$} \\
\hline 9 & E-H & {$[0.125,0.375]$} & {$[0.232,0.332]$} & {$[0.789,0.895]$} & {$[0.8,1]$} \\
\hline 10 & F-G & {$[0.375,0.583]$} & {$[0.415,0.485]$} & {$[0.895,0.947]$} & {$[0.4,0.6]$} \\
\hline 11 & F-I & {$[0.708,0.917]$} & {$[0.517,0.732]$} & {$[0.737,0.842]$} & {$[0.8,0.9]$} \\
\hline 12 & G-K & {$[0.125,0.333]$} & {$[0.683,0.854]$} & {$[0.842,0.895]$} & {$[0.6,0.8]$} \\
\hline 13 & H-J & {$[0.125,0.208]$} & {$[0.293,0.402]$} & {$[0.526,0.684]$} & {$[0.2,0.4]$} \\
\hline 14 & I-M & {$[0.167,0.333]$} & {$[0.232,0.341]$} & {$[0.632,0.737]$} & {$[0.5,0.7]$} \\
\hline 15 & J-L & {$[0.125,0.333]$} & {$[0.293,0.390]$} & {$[0.579,0.684]$} & {$[0.7,0.9]$} \\
\hline 16 & K-M & {$[0.333,0.458]$} & {$[0.488,0.695]$} & {$[0.474,0.579]$} & {$[0.5,0.6]$} \\
\hline 17 & K-N & {$[0.708,0.875]$} & {$[0.734,0.805]$} & {$[0.789,0.842]$} & {$[0.4,0.5]$} \\
\hline 18 & L-M & {$[0.583,0.667]$} & {$[0.610,0.707]$} & {$[0.632,0.789]$} & {$[0.4,0.6]$} \\
\hline 19 & M-O & {$[0.667,0.833]$} & {$[0.561,0.646]$} & {$[0.737,0.842]$} & {$[0.3,0.5]$} \\
\hline 20 & O-P & {$[0.792,1]$} & {$[0.659,0.732]$} & {$[0.474,0.579]$} & {$[0.5,0.7]$} \\
\hline 21 & O-Q & {$[0.583,0.708]$} & {$[0.639,0.756]$} & {$[0.789,0.895]$} & {$[0.5,0.6]$} \\
\hline 22 & P-R & {$[0.375,0.5]$} & {$[0.585,0.698]$} & {$[0.632,0.737]$} & {$[0.2,0.3]$} \\
\hline 23 & Q-S & {$[0.625,0.750]$} & {$[0.732,0.768]$} & {$[0.789,0.842]$} & {$[0.4,0.5]$} \\
\hline 24 & R-T & {$[0.208,0.375]$} & {$[0.410,0.537]$} & {$[0.684,0.789]$} & {$[0.5,0.7]$} \\
\hline 25 & S-U & {$[0.625,0.708]$} & {$[0.561,0.659]$} & {$[0.526,0.632]$} & {$[0.5,0.8]$} \\
\hline 26 & T-U & {$[0.667,0.917]$} & {$[0.927,1]$} & {$[0.842,0.947]$} & {$[0.7,0.9]$} \\
\hline 27 & N-V & {$[0.583,0.750]$} & {$[0.707,0.805]$} & {$[0.684,0.737]$} & {$[0.6,0.8]$} \\
\hline 28 & U-V & {$[0.542,0.750]$} & {$[0.756,0.854]$} & {$[0.789,0.895]$} & {$[0.4,0.6]$} \\
\hline 29 & V-W & {$[0.833,0.917]$} & {$[0.683,0.793]$} & {$[0.737,0.895]$} & {$[0.5,0.7]$} \\
\hline & & & & & \\
\hline & & & \\
\hline 14 &
\end{tabular}

Tab. 3: Time, cost, quality and risk based critical paths

\begin{tabular}{c|c|c}
\multirow{2}{*}{ Criterion } & \multicolumn{2}{|c}{ Goal values } \\
\hline \multirow{2}{*}{ Time } & Lower bound & 5.709 \\
\cline { 2 - 3 } & Upper bound & 7.874 \\
\hline \multirow{2}{*}{ Cost } & Lower bound & 7.228 \\
\cline { 2 - 3 } & Upper bound & 8.562 \\
\hline \multirow{2}{*}{ Quality } & Lower bound & 8.895 \\
\cline { 2 - 3 } & Upper bound & 10.052 \\
\hline \multirow{2}{*}{ Risk } & Lower bound & 5.9 \\
\cline { 2 - 3 } & Upper bound & 8 \\
\hline
\end{tabular}


deal with lack of knowledge and uncertainty about these approximations. Therefore, project planning is recognized as an uncertain planning problem. To deal with these conditions, a grey multi-objective programming-based model is proposed in this paper to address the critical path of the project. The time, cost, quality, and risk factors of the activities are approximated by grey numbers to deal with their uncertainty. Then, a multi-objective programming model is extended to find the critical path of the project considering multiple criteria. A goal programming based approach is then developed to solve the multiobjective uncertain critical path determination problem. Application of the proposed method is examined in a numerical example. Considering abilities of the current optimization packages, the proposed method can be easily applied in the real world projects.

\section{References}

Amoozad Mahdiraji, H., Razavi, H., \& Pourjam, R. (2011). A Grey Mathematical Programming model to Time-Cost Trade-offs in Project Management under Uncertainty. In International Conference on Grey Systems and Intelligent Service (pp. 709-719). Nanjing, China: IEEE.

Amiri, M., \& Golozari, F. (2011). Application of fuzzy multi-attribute decision making in determining the critical path by using time, cost, risk, and quality criteria. International Journal of Advanced Manufacturing Technology, 54(1-4), 393-401. doi:10.1007/s00170-010-2928-4.

Branke, J., Deb, K., Miettinen, K., \& Slowinski, R. (2008). Multiobjective Optimization: Interactive and Evolutionary Approaches. Berlin, Springer-Verlag.

Chanas, S., \& Zielinski, P. (2001). Critical path analysis in the network with fuzzy activity times. Fuzzy Sets and Systems, 122(2), 195204. doi:10.1016/S0165-0114(00)00076-2.

Chanas, S., \& Zielinski, P. (2002). The Computational Complexity of the Criticality Problems in A network with Interval Activity Times. European Journal of Operational Research, 136(3), 441-450. doi:10.1016/ S0377-2217(01)00048-0.

Charnes, A., \& Cooper, W.W. (1961). Management models and industrial applications of linear programming. New York: Wiley.

Chen, S. (2007). Analysis of critical paths in a project network with Fuzzy Activity Times. European Journal of Operational
Research, 183(1), 442-459. doi:10.1016/j. ejor.2006.06.053.

Chen, S., \& Hsueh, Y. (2008). A simple approach to fuzzy critical path analysis in Project Networks. Applied Mathematical Modelling, 32(7), 1289-1297. doi:10.1016/j. apm.2007.04.009.

Cristobal, J.R.S. (2013). Critical path definition using multicriteria decision making: PROMETHEE method. Journal of Management in Engineering, 29(2), 158-163. doi:10.1061/ (ASCE)ME.1943-5479.0000135.

Deng, J. (1982). Control problems of grey system. Systems \& Control Letters, 1(5), 288294. doi:10.1016/S0167-6911(82)80025-X.

Deng, J. (1989). Introduction to grey system theory. The Journal of Grey Theory, 1(1), 1-24. Retrieved from http://www.researchinformation. co.uk/grey/IntroGreySysTheory.pdf.

Elizabeth, S., \& Sujatha, L. (2013). Fuzzy Critical Path Problem for Project Network. International Journal of Pure and Applied Mathematics, 85(2), 223-240. doi:10.12732/ ijpam.v85i2.4.

Fortin, J., Zielinski, P., Dobuios, D., \& Fargier, H. (2010). Criticality analysis of activity networks under interval Uncertainty. Journal of Scheduling, 13(6), 609-627. doi:10.1007/ s10951-010-0163-3.

Han, T.C., Chung, C.C., \& Liang, G.S. (2006). Application of Fuzzy Critical Path Method to Airport Cargo's Ground Operation System. Journal of Marine Science and Technology, 14(3), 139-146. Retrieved from http://jmst.ntou.edu.tw/marine/14-3/139-146. pdf.

Huang, G., Beatz, B., \& Party, G. (1996). Development of A Grey Critical Path Method for Construction planning. Engineering Optimization, 28(3), 157-174. doi:10.1080/03052159708941130.

Ida, M. (2005). Efficient solution generation for multiple objective linear programming based on extreme ray generation method. European Journal of Operational Research, 160(1), 242251. doi:10.1016/j.ejor.2003.08.039.

Kaur, P., \& Kumar, A. (2014). Linear programming approach for solving fuzzy critical path problems with fuzzy parameters. Applied Soft Computing, 21(August), 11-21. doi:10.1016/j.asoc.2014.03.017.

Kelly, J. (1961). Critical-path planning and scheduling: Mathematical Basis. Operations Research, 9(3), 296-320. 
Retrieved from http://ageconsearch.umn.edu/ bitstream/8803/1/32010036.pdf.

Kumar, P., \& Kaur, A. (2010). A new Method for Fuzzy Critical Path Analysis in Project Networks with a New Representation of Triangular Fuzzy Numbers. Applications and Applied Mathematics: An International Journal, 5(10), 345-369. Retrieved from http://www.pvamu.edu/include/Math/AAM/ AAM $\% 2$ Vol. $\% 205, \% 20$ Issue $\% 2010 \% 20$ (December\%202010)\%20Updated\%2012-212011/08_Kumar_R280_Vol_5_Issue_2.pdf.

Li, Q.X., Liu, S., \& Wang, N.A. (2014). Covered solution for a grey linear program based on a general formula for the inverse of a grey matrix. Grey Systems: Theory and Applications, 4(1), 72-94. doi:10.1108/GS-102013-0023.

Liang, G., \& Han, T. (2004). Fuzzy Critical Path for Project Network. International Journal of Information and Management Science, 15(4), 29-40.

Lin, Y., Chen, M.Y., \& Liu, S. (2004). Theory of grey systems: capturing uncertainties of grey information. Kybernetes, 33(2), 196-218. doi:10.1108/03684920410514139.

Liu, S., \& Lin, Y. (2006). Grey information: theory and practical applications. London: Springer.

Liu, S., \& Lin, Y. (2010). Grey systems: theory and applications. Berlin: Springer.

Madhuri, K., Saradhi, P., \& Shankar, N. (2013). Fuzzy Linear Programming Model for Critical Path Analysis. International Journal of Contemporary Mathematical Sciences, 8(2), 93-116. Retrieved from https://www. researchgate.net/publication/264909765_ Fuzzy_linear_programming_model_for_ critical_path_analysis.

Malcolm, D., et al. (1959). Application of a Technique for Research and Development Program Evaluation. Operations Research, 7(5), 646-669. doi:10.1287/opre.7.5.646.

Prade, H. (1979). Using fuzzy set theory in a scheduling problem: a case study. Fuzzy Sets and Systems, 2(2), 153-165. doi:10.1016/01650114(79)90022-8.

Rasmy, M.H., Abdelsalam, H.M., \& Ragab, R. (2008). Multi-objective time-cost trade-off analysis in critical chain project networks using Pareto simulated annealing. In Proceedings of the 6th International Conference on Informatics and Systems (INFOS), Cairo: Faculty of Computers \& Information, Cairo University.
Retrieved from http://infos2008.fci.cu.edu.eg/ infos/DSS_01_P001-011.pdf.

Razavi Hajiagha, S.H., Amoozad Mahdiraji, H., \& Hashemi, S.S. (2014). A hybrid model of fuzzy goal programming and grey numbers in continuous project time, cost, and quality tradeoff. International Journal of Advanced Manufacturing Technology, 71(1-4), 117-126. doi:10.1007/s00170-013-5463-2.

Razavi Hajiagha, S.H., Amoozad Mahdiraji, H., \& Hashemi, S.S. (2013). Multi-objective linear programming with interval coefficients a fuzzy set based approach. Kybernetes, 42(3), 482-496. doi:10.1108/03684921311323707.

Razavi, S.H., Akrami, H., Hashemi, S.S., \& Amoozad Mahdiraji, H. (2015). An Integer grey goal programming for project time, cost and quality tradeoff. Engineering Economics, 26(1), 93-100. doi:10.5755/j01.ee.26.1.9930.

Shahsavaripour, N., et al. (2010). Calculating the Project Network Critical Path in Uncertainty Conditions. International Journal of Engineering Technology, 2(2), 136-140.

Shankar, N.R., \& Saradhi, P.B. (2011). Fuzzy Critical Path Method in Interval-Valued Activity Network. International Journal of Pure and Applied Mathematics, 3(2), 72-79. Retrieved from http://ijopaasat.in/yahoo_site_admin/ assets/docs/2_IJPASTVol_3_No_2.23614347. pdf.

Shankar, N.R., Sireesha, V., \& Rao, P. (2010). An Analytical Method for Finding Critical Path in a Fuzzy Project Network. International Journal of Contemporary Mathematical Sciences, 5(20), 953-962. Retrieved from https://www. researchgate.net/publication/215527889_An_ analytical_method_for_finding_critical_path_ in_a_fuzzy_project_network.

Shankar, N.R., Sireesha, V., \& Rao, P. (2010). Critical Path Analysis in the Fuzzy Project Network. Advances in Fuzzy Mathematics, 5(3), 285-294. Retrieved from https://www. researchgate.net/publication/215527904 Critical_Path_Analysis_in_the_Fuzzy_Project_ Network.

Shankar, N.R., Sireesha, V., Rao, K., \& Vani, N. (2010). Fuzzy Critical Path Method Based on Metric Distance Ranking of Fuzzy Numbers. International Journal of Mathematical Analysis, 4(20), 995-1006. Retrieved from https://www. researchgate.net/publication/215527891_ Fuzzy_critical_path_method_based_on_ metric_distance_ranking_of_fuzzy_numbers.

Sireesha, V., \& Shankar, N.R. (2010). 


\section{Ekonomika a management}

A New Approach to find Total Float time and Critical Path in a fuzzy Project Network. International Journal of Engineering Science and Technology, 2(4), 600-609. Retrieved from http://citeseerx.ist.psu.edu/viewdoc/download? doi=10.1.1.189.856\&rep=rep1\&type=pdf.

Sireesha, V., Rao, K., Shankar, N.R., \& Babu, S. (2012). Critical path analysis in the network with fuzzy interval numbers as activity times. International Journal of Engineering Science and Technology, 4(3), 823-833.

Taha, H.A. (2003). Operations Research: An Introduction. New Jersey: Prentice Hall.

Tanino, T., Tanaka, T., \& Inuiguchi, M. (2003). Multi-Objective Programming and Goal Programming: Theory and Applications. Berlin: Springe-Verlag.

Taylor, B. (1996). Introduction to Management Science. New York: Prentice-Hall.

Traub, J.F., \& Werschulz, A.G. (1998). Complexity and Information. Roma: Academia Nazionale Dei Lincei.

Wang, M.L., \& Wang, H.F. (2001). Interval analysis of a fuzzy multi objective linear programming. International Journal of Fuzzy Systems, 34, 558-568.
Zadeh, L.A. (1965). Fuzzy Sets. Information and Control, 8(3), 338-353. Retrieved from http://www.cs.berkeley.edu/ zadeh/papers/ Fuzzy $\% 20$ Sets-Information $\% 20$ and $\% 20$ Control-1965.pdf.

Zammori, F.A., Braglia, M., \& Frosolini, M. (2009). A fuzzy multi-criteria approach for critical path definition. International Journal of Project Management, 27(3), 278-291. doi:10.1016/j. ijproman.2008.03.006.

Hannan Amoozad Mahdiraji, Ph.D. University of Tehran Faculty of Management h.amoozad@ut.ac.ir

Seyed Hossein Razavi Hajiagha, Ph.D. Khatam Institute of Higher Education Department of Management s.razavi@khatam.ac.ir

Shide Sadat Hashemi Saramadan Andisheh Avina Co. Department of Management shide_hashemi@yahoo.com

Prof. Edmundas Kazimieras Zavadskas, Ph.D. Vilnius Gediminas Technical University Faculty of Civil Engineering Edmundas.zavadskas@vgtu.It 


\title{
Abstract
}

\section{A GREY MULTI-OBJECTIVE LINEAR MODEL TO FIND CRITICAL PATH OF A PROJECT BY USING TIME, COST, QUALITY AND RISK PARAMETERS}

\author{
Hannan Amoozad Mahdiraji, Seyed Hossein Razavi Hajiagha, \\ Shide Sadat Hashemi, Edmundas Kazimieras Zavadskas
}

\begin{abstract}
A project is a series of related activities which are organized to reach a defined goal or satisfy a certain need. Project management plays an important role in different fields of human life. The amount of resources spent on a project renders management of these resources a sensitive task. Determinant factors' influencing the payoffs of a project mainly encompasses time, cost, quality and also the risk of each activity. Therefore, a critical path method is presented to find the longest path of a project completion time in order to draw managers' attention to the critical activities. Critical path method is a well-known and widely accepted method to find the critical activities of a project and to concentrate on them for accomplishment of the project without any deviation. Classical critical path methods usually consider only a time factor, but growing complexity and importance of projects entail cost, quality and risk as the critical factors to be considered in project management. Due to the unavailability of certain information relating each factor of each activity, considering a novel approach to deal with such vague and unstable situations is really a controversial issue. Thus, another challenge of the project management contains uncertainty for approximating time, cost, quality, and risk factors of the project activities. Taking into account these two challenges, a grey multi-objective critical path model is proposed in this paper, where parameters of the activities are evaluated as grey numbers, dealing with their uncertainty. Meanwhile, a goal programming based method is illustrated to solve the problem of critical path identification, considering four considerable criteria including time, cost, quality, and risk. Eventually, a numerical example is represented to address applicability of the proposed method.
\end{abstract}

Key Words: Critical path method, project network, time, cost, quality, risk, grey numbers, multiobjective programming, goal programming.

JEL Classification: C02, C61, M11.

DOI: 10.15240/tul/001/2016-1-004 